\title{
A PARATOPIA DO ESTIGMA DO DISCURSO UM HOMEM CHAMADO CAVALO É MEU NOME, DE STELA DO PATROCÍNIO
}

Ramon Silva CHAVES

\section{Introdução}

Neste capítulo, o evento sobre o enunciado literário que mais nos interessa é a criação. É comum que a literatura seja associada à vida de um sujeito, suas capacidades intelectuais e os espaços, quer físicos, quer sociais, que este tenha frequentado. De modo evidente, muitas dessas características corroboram a recepção desses enunciados ampliando a mística ao seu redor. Assim, tomar um texto como literário em muitas ocasiões quer dizer tomar, também, o entendimento de que esse texto deve ser lido a partir da vida de seu autor. 
No caso de nosso estudo, nosso tema é o movimento de criação do discurso literário Um homem chamado cavalo é meu nome, de Stela do Patrocínio. Esse recorte de pesquisa é o primeiro capítulo do livro de poesias Reino dos bichos e dos animais é meu nome, publicado em 2001. Esse tema nasce das condições sócio-históricas e culturais de produção do discurso mencionado, uma vez que seu processo de criação justifica o enunciado como literário.

A autora de nosso corpus é Stela do Patrocínio (1941-1992), sujeito que passou os trinta últimos anos de sua vida como interna da Colônia Juliano Moreira, sanatório carioca, com um diagnóstico de esquizofrenia, sem visitas de familiares ou amigos durante toda a sua internação. A singularidade da vida de Stela do Patrocínio, contudo, não é o bastante para observar o processo de criação de Um homem chamado cavalo é meu nome, pois esse enunciado não foi produzido pelas dinâmicas convencionais à literatura.

Stela do Patrocínio, durante sua internação, nunca escreveu muita coisa além de algumas palavras em papéis que lhe foram disponibilizados pela equipe da professora e artista plástica Nelly Gutmacher. A mencionada artista foi convidada pela diretoria da Colônia Juliano Moreira para instalar um ateliê para a humanização do local, o que possibilitou que Stella fosse ouvida a partir da interpretação artística. Desse modo, o que agora pode ser lido como literatura em Um homem chamado cavalo é meu nome, foi, antes, uma série de entrevistas concedidas por Stela do Patrício feitas por Carla Guagliardi, uma das alunas de Nelly Gutmacher. Mas os eventos curiosos desse processo de criação literário não param neste ponto.

A fala de Stela, que fora gravada por Carla Guagliardi, foi transcrita por outra aluna de Nelly Gutmacher, Mônica Ribeiro de Sou$\mathrm{za}$, e foram essas transcrições que chegaram à poeta, psicanalista e 
filósofa Viviane Mosé, quem editou, ajustou e publicou como livro de poesia Reino dos bichos e dos animais é meu nome, pela editora Azougue, no Rio de Janeiro.

Conquanto seja certo que todas as publicações literárias modernas passam por um processo de muitos ajustes, modulações, correções e acertos, feitos por inúmeras pessoas, o processo criador literário observado por nosso estudo, não é o editorial apenas, mas aquele que tem um fio condutor que o coloca numa fronteira entre o delírio e o artístico, que é a loucura.

Neste pano de fundo, analisamos Um homem chamado é cavalo é meu nome a partir dos pressupostos teórico-metodológicos da Análise de Discurso de inspiração francesa, sobretudo as noções de discurso constituinte literário e paratopia de identidade, proposições de Maingueneau (2006).

Além disso, tencionamos a categoria paratopia de identidade no discurso analisado e observamos que o processo de criação literária é orientado pelo estigma da internação psiquiátrica, a loucura. Por isso, valemo-nos da noção de estigma (GOFFMAN, 2001) e paratopia do estigma (CHAVES, 2018) para constituir nossa análise.

Nossa metodologia de análise mostrou-se produtiva, uma vez que paratopia do estigma é a força motriz literária que garante o sentido para o nosso objeto de pesquisa, pois o estigma é o responsável pela tomada do enunciado como literário em uma topos que não se estabelece como enunciado totalmente tópico, nem como enunciado não tópico, mas no equilíbrio entre uma zona problemática admitida pelos analistas do discurso como a paratopia.

O capítulo tem três seções: a primeira se debruça sobre formulação de nosso corpus e suas condições sócio-históricas e culturais 
de produção, a segunda seção discute a noção de discurso literário e paratopia do estigma, a terceira propõe uma análise de discurso do corpus.

\section{A Literatura como discurso.}

O que é a Literatura? Definitivamente, não estamos diante de uma pergunta fácil de ser respondida. Aliás, parece-nos demasiado pretensioso tentar responder essa pergunta neste capítulo; afinal, muitas e muitos autores que se dedicaram a delinear um contorno confortável mesmo que exíguo do campo literário. Em especial, podemos citar Pierre Bourdieu que em As regras da arte: gênese e estrutura do campo literário (1992) opta por entender a Literatura como um campo artístico estruturalmente responsivo à sociedade, ou, mais longinquamente, os estudos de Mikhail Bakhtin em Estética da Criação Verbal, (2003), de onde emerge uma produtiva reflexão sobre "os gêneros do discurso".

A seleção dos autores supracitados não é aleatória; parte, pois, da importância aqui dada à análise material do texto literário como fenômeno textual e concreto e, ao mesmo tempo, de sua emergência social e histórica. Desse modo, a pergunta que inicia este capítulo é nosso pano de fundo para entender um objeto que, ao nosso olhar, parece social, histórico e textual na mesma proporção.

Para muitos, a instabilidade e pluralidade do campo literário pode ser motivo de insegurança epistemológica e é para diminuir essa instabilidade que muitos foram os esforços para definir a Literatura, por meio de sua própria instabilidade, porque enunciados de natureza social e estrutura textual distintos foram compreendidos, à revelia de observações conservadoras, como literárias. A 
reconhecida intelectual da Literatura, Marisa Lajolo, tenta, desse modo, simplificar a acepção de Literatura por sua imprevisibilidade, entendendo que para a pergunta "o que é literatura?":

a resposta é simples. Tudo isso é, não é e pode ser que seja literatura. Depende do ponto de vista, do sentido que a palavra tem para cada um, da situação na qual se discute o que é literatura (LAJOLO, 1984, p. 15).

Pode ser que o caminho mais fácil para discutir o campo literário seja o de extrapolar os limites fronteiriços de qualquer análise estruturalista como fez a professora Lajolo. Desse modo, a Literatura passa a ser observada como objeto reconhecido como literário, por conseguinte, a literatura é uma manifestação comunicativa possível em determinada comunidade.

Assim, parece-nos mais confortável substituir a pergunta "O que é literatura?” por "quais as condições de manifestação da Literatura?", uma vez que não se pode contornar o campo, é mais prudente observar sua expansão e manifestação.

Partimos, portanto, dessa conjuntura problemática para perguntar "quais as condições de manifestação literária de Um homem chamado cavalo é meu nome, de Stela do Patrocínio?", recorte do livro de poesias Reino dos Bichos e dos animais é meu nome, organizado e apresentado pela filósofa Viviane Mosé.

O nosso recorte materializa a problemática acerca da Literatura discutida até aqui, pois trata-se de um texto produzido sob condições peculiares. De antemão, poderíamos mencionar o fato de que se trata de manifestação oral já que as poesias encontradas no livro foram gravadas, pois sua autora estava sendo "entrevistada". A 
responsável pela entrevista é Nelly Gutmacher, uma artista plástica que interpretou o "falatório"33 de Stela do Patrocínio, interna da Colônia de Alienado Juliano Moreira, como artístico.

O texto, ora analisado, passou por um processo criador curioso, afinal essa produção, reconhecida como literária, nasceu em um terreno singular de toda a produção de literatura de que se tem notícia. Assim, parece-nos eficaz produzir uma análise capaz de levantar os liames de composição desse terreno literário e, por isso mesmo, é produtivo tomar o nosso objeto de estudo como discurso, pois esse enfoque garante a compleição de um enunciado cujas condições interferem efetivamente na enunciação. Por outras palavras, entender o nosso escopo como discurso é aceitar a união radical entre o plano textual e suas condições de produção. Tal posicionamento foi definido, por Eagleton (2007, p. 90), como um olhar sobre o discurso:

Poems do things to us as well as say things to us; they are social events as well as verbal artefacts. And the notion of a verbal event - of language as a practical activity - was known to the ancients as rhetoric, as we have seen already. Rhetoric means language organised in such a way as to achieve certain determinate ends, and this involves taking account of a whole number of considerations: the material nature of language itself; the way its various formal devices typically operate; the nature and capacities of its audience; and the social situation in which all this takes place. One modern term for this is 'discourse', which means language grasped as a concrete social occurrence inseparable from its context.

33 Expressão utilizada inúmeras vezes por Stela para referir-se ao que dizia. 
Ao considerarmos Um homem chamado cavalo é meu nome discurso, optamos por observá-lo sob a óptica do plano textual, linguístico, e do plano dos agentes envolvidos em sua produção de maneira simultânea. Assim, para a análise, são importantes aspectos históricos, sociais, e textuais sem preterir nenhum dos traços composicionais, porque nosso interesse é

o de apreender o discurso como intricação de um texto e de um lugar social, o que significa dizer que seu objeto não é nem a organização textual, nem a situação de comunicação, mas aquilo que as une por intermédio de um dispositivo de enunciação específico. Esse dispositivo pertence simultaneamente ao verbal e ao institucional: pensar os lugares independentemente das palavras que eles autorizam, ou pensar as palavras independentemente dos lugares com os quais elas estão implicadas significaria permanecer aquém das exigências que fundam a análise do discurso (MAINGUENEAU, 2007, p. 19).

Entender, desse modo, Um homem chamado cavalo é meu nome como discurso literário, significa supor que as condições de enunciação desse discurso emergem reguladas por suas condições sócio-históricas e culturais de circulação. Essas condições são reveladas na/pela enunciação do texto. Desse modo, passamos a discutir o nosso recorte como corpus de uma Análise do discurso.

\section{O discurso Um homem chamado cavalo é meu} nome

O objeto de nossa análise é o primeiro capítulo de Reino dos bichos e dos animais é meu nome, de Stela do Patrocínio (doravante 
Stela). Esse capítulo traz enunciados que informam sobre a chegada e a permanência do enunciador em um "hospital" (MOSÉ, 2001). Muito dessa enunciação, como é fácil perceber, nasce da experiência de Stela ao ser internada na Colônia Juliano Moreira ${ }^{34}$. Stela esteve entre as décadas 1960 e 1990 - últimos anos de sua vida - como interna da Colônia Juliano Moreira, lugar onde enunciou e foi gravada a obra de onde extraímos o nosso objeto.

Um homem chamado cavalo é meu nome é, portanto, um agrupamento de enunciados gravados pela artista plástica Nelly Gutmacher e pela estagiária Carla Guagliardi. A pedido da psicóloga Denise Corrêa, Gutmacher montou um ateliê de artes sem fins terapêuticos na ala feminina da Colônia onde viveu Stela. Por dois anos, o espaço fora frequentado pela interna que pouco produziu no campo visual artístico. No entanto, a sua fala chamou a atenção da professora e artista plástica que a entrevistou e gravou entre 1986 e 1988.

A mulher negra, alta, imponente, que "parecia uma rainha" como descreveu Viviane Mosé (2001), era fácil de ser notada. No entanto, o que mais surpreendeu o núcleo artístico que visitava a Colônia Juliano Moreira era a forma como Stela falava. Tanto surpreendeu que a transcrição de alguns desses enunciados ajudaram a compor a exposição "Ar Subterrâneo" no Largo do Paço, 1988, fruto da residência artística na Colônia. Ainda, fragmentos da "fala" de Stela foram utilizados em apresentações musicais do grupo Boato, do músico conhecido como Cabelo, e da peça "Stela do Patrocínio, óculos, vestido azul, sapato preto, bolsa branca e ... doida" monólogo interpretado por Clarisse Baptista e dirigido por Nena Mubárac, apresentado em Rio Branco, Rio de Janeiro e Curitiba. No entanto, a grande repercussão do reconhecimento de Stela do Patrocínio como poeta se deveu à Viviane Mosé, que

34 Instituto Municipal de Assistência à Saúde Juliano Moreira. 
durante sua pesquisa de doutorado foi convidada pelo Museu Nise da Silveira para um trabalho no Instituto Municipal de Assistência à Saúde Juliano Moreira (IMASJM). Neste trabalho, que tinha como objetivos organizar os materiais escritos de pacientes em uma publicação e realizar oficinas de literatura com os internos, ela teve contato, pela primeira vez, com o "falatório" de Stela. Ela se interessou pelo conteúdo do "falatório" e propôs a organização do livro que foi publicado, em 2001, pela editora "Azougue Editorial" e indicado ao Prêmio Jabuti de 2002 na categoria Psicologia e Educação. Recebeu nova edição em 2009 (ZARA, 2014, p. 12 e 13).

Repare nesse fato curioso: Reino dos bichos e dos animais é meu nome é um discurso cujo processo de criação é inusitado: dele emerge um enunciador que foi construído por etapas, diferentemente do que se espera no senso comum para um enunciador. No prefácio de Reino dos bichos e dos animais é meu nome, encontra-se a seguinte ressalva de Mosé (2001, p. 26):

A primeira coisa que preciso ressaltar, em relação à presente publicação, é que se trata de uma transposição: o que foi uma fala aparece aqui como escrita. Trata-se de dois universos distintos. Não apenas porque desconhecemos o que Stela teria escrito, já que escrever respeita um outro tipo de estruturação de linguagem, como também porque, ao transpor essa fala para a escrita, não estaremos reproduzindo o que ela disse. 
$\mathrm{Na}$ primeira etapa, Stela enuncia uma entrevista; na segunda etapa, há a transposição. Poderia uma entrevista cujas enunciadoras eram uma artista plástica e uma interna de manicômio ser literatura? A resposta é impossível, uma vez que não é assim que o texto veio a público. Viviane Mosé assume que há uma distinção entre o que foi "falado" e o que "está escrito". Embora exista similaridade, $\mathrm{o}$ ato de produzir o texto, não o tornou literário, existe um processo de criação por "camadas".

A linha "editorial" de Mosé ainda fez outras adaptações na enunciação que passaremos a chamar de "enunciação origem". Nas palavras da filósofa, ainda no prefácio "a primeira preocupação que tive, ao iniciar o trabalho de organização deste livro, foi encontrar a sonoridade do texto" (MOSÉ, 2001, p. 27). Mais do que a transposição, o enunciado origem foi identificado como "poesia", mas essa identificação não é autônoma, pois a poesia se marca por uma organização textual reconhecida. $\mathrm{O}$ enunciado origem deu a Mosé o conteúdo passivo de ser apreendido como literário, mas coube àquela dar-lhe forma

Form concerns such aspects of the poem as tone, pitch, rhythm, diction, volume, metre, pace, mood, voice, address, texture, structure, quality, syntax, register, point of view, punctuation and the like, whereas content is a matter of meaning, action, character, idea, storyline, moral vision, argument and so on (EAGLETON, 2007, p. 66).

Desse modo, de um lado do, temos um enunciado origem que marca experiências, pontos de vista, uso específico da língua; de outro, temos uma organizadora e editora que transpõe o enunciado em uma forma marcada por ritmo, a seleção semântica dos temas, 
a correção gramatical ${ }^{35}$. Além disso, não se pode desconsiderar o fato de que as falas gravadas foram transcritas por estagiários da Colônia e do grupo artístico liderado por Gutmacher, o que torna mais complexo o cenário sócio-histórico da produção enunciativa de Um homem chamado cavalo é meu nome.

Especificamente sobre nosso recorte, Mosé descreve que é "onde se depara, enxerga, localiza o hospital, sua 'doença', sua prisão, sua condição: 'ficar pastando"' (MOSÉ, 2001, p. 29). Nessa senda, trata-se de um agrupamento de enunciados cujo campo semântico revela um espaço manicomial, de tratamento, de apartamento, mostrado pelo enunciador como "hospital".

Esse agrupamento compreende dez enunciados reunidos por Mosé que não possuem uma forma rígida. O segundo enunciado, por exemplo, não está organizado por versos, apresenta um único e grande parágrafo como se a enunciação fora posta num só golpe. Os demais possuem versos: alguns longos, outros curtos. Como não há títulos, chamaremos os enunciados de Um homem chamado cavalo é meu nome por números: o primeiro enunciado é o I, e assim sucessivamente.

\section{Lugar de maluco louco doido}

Um homem chamado cavalo é meu nome enuncia sobre o estar em condição manicomial. É, portanto, um enunciado marcado por um enunciador interno, recluso, fechado, resultado de um processo sócio-histórico que conferiu às pessoas chamadas "loucas" estatuto de prisioneiros, marginais, apartadas dos ditos "não loucos".

35 Mosé menciona que fez poucas correções gramaticais, e fala especificamente da alteração do "Tô" por "Estou”. Mesmo assim, consideramos que a alteração incide diretamente na produção de efeitos de sentido. 
À loucura coube, no Ocidente, a contraposição: sujeitos marcados como aqueles que não estão sãos, os doentes, cujas vozes são inaudíveis, porque o que é dito não faz sentido. O "louco" é aquele que pode ser identificado como tal, mas quais são os signos da loucura? Sobre o estatuto de "louco e interno", Foucault (1972, p. 196) ensina,

Como é que se reconhece esse louco, tão facilmente identificável ainda um século antes em seu perfil bem recortado, e que agora deve cobrir com uma máscara uniforme tantos rostos diferentes? Como é que se pode apontá-lo, sem errar, na proximidade cotidiana que o mistura a todos os não-loucos e no inextricável cadinho dos traços de sua loucura com os signos obstinados de sua razão? Questões que o prudente se coloca mais que o sábio, o filósofo mais que o médico e todo o rebanho atento dos críticos, céticos e moralistas.

O historiador Michel Foucault falava da construção histórica do "louco"; no entanto, a sua reflexão nos vale na medida em que configura o "louco" como aquele que está em contraposição ao "não louco". Essa concepção, maniqueísta acerca da razão, modelou, pelas mãos do Estado, um regime de exclusão do grupo de sujeitos que se perfazem do estigma ${ }^{36} \mathrm{da}$ loucura.

Desse modo, as condições sócio-históricas e culturais de nosso objeto são, para além daquelas expostas na seção anterior, o manicômio e a loucura. Embora sejam essas concepções justapostas, es-

36 Esta noção será desenvolvida a seguir, na seção Problemas da paratopia de identidade e a paratopia do estigma em que discutiremos a noção de estigma com base nos pressupostos de Goffman em Estigma: notas sobre a manipulação da Identidade deteriorada, 2001. 
tamos diante de um enunciador que, nas palavras de Mosé (2001, p. 24 e 25),

era capaz de lançar um olhar sobre a condição asilar e, ao mesmo tempo, dimensionar esse olhar em uma interpretação do que seria a condição humana: uma fala atravessada por outras falas. Stela falava de sua condição como quem se vê fora dela, o que quer dizer se desdobrar, ou seja, produzir uma dobra sobre si mesma. Mais do que isso, Stela falava de sua própria fala, o que implica em uma operação ainda mais elaborada: falar sobre o falar nada mais é do que mais uma vez de desdobrar.

Temos, pois, que um enunciado marcado pelo manicômio adquire a própria voz num espaço reservado ao silêncio social. O enunciador do discurso origem está entrecortado pela função "louco", o que garante o seu direito à fala, à enunciação; é, portanto, sua condição de exílio. Ainda, é sua fala lúcida, e contraposta aos demais, que relega, segundo Mosé, ao enunciador o campo literário.

O falar louco, mas lúcido, no manicômio, instaura a problemática que ora passamos a discutir sob o escopo teórico metodológico da Análise do Discurso. Levantamos aqui traços de composição do discurso Um homem chamado cavalo é meu nome que tangem à estrutura composicional e à tematização do discurso para empregarmos termos de Bakhtin (2009).

Agora que tornamos o olhar disperso e talvez fragmentado, resta-nos compor o quadro partindo da observação teórica da Análise do discurso. 


\section{O discurso literário Um homem chamado cavalo é meu nome: paratopia de identidade no discurso constituinte literário}

Nesta seção, discutimos a condição de criação do discurso literário, a paratopia. Para isso, apresentamos a noção de discurso constituinte e, em seguida, a noção de paratopia de identidade (MAINGUENEAU, 2006). Dadas as condições de produção do nosso corpus, evidenciamos a necessidade de propor alargamento da concepção estudada por Maingueneau, por isso abordaremos também a paratopia do estigma, conceito proposto por Chaves (2018).

Como vimos, tratamos aqui de Discurso literário, mas observar a Literatura como discurso significa associá-la a um campo da linguagem vasto demais e, de certo modo, corre-se o risco de entender os enunciados literários pela mesma óptica com a qual entendemos enunciados não literários e, por conseguinte, destituir a Literatura de um espaço de privilégio que ela goza em relação a outros discursos.

Distinguir a Literatura impõe-nos a reflexão que ela não tem em si um lugar de emergência, uma instituição, um prédio do Estado ou privado, capaz de garantir a sua enunciação. Além disso, não há um autor capaz, por si mesmo, de garantir que qualquer enunciado seu seja recebido como literário ou não.

Outros gêneros têm seu estatuto garantido por meio de instâncias exteriores que os validam. Por exemplo o enunciado jornalístico está garantido pela instituição que o resguarda e o autoriza. A enunciação literária corrompe essa lógica e ao invés de ser validada por algo que lhe é exterior, valida a si mesma, num processo 
de auto e heteroconstituição. Desse modo, só um enunciado que é auto e heteroconstituinte pode ser chamado, de acordo com Maingueneau (2006), como discurso constituinte.

$\mathrm{O}$ discurso constituinte engendra as próprias regras de enunciação: é o archeion de uma coletividade, simboliza, desse modo, os prédios e os arquivos do Estado, e seus próprios limites enunciativos. Falar em termos de discurso constituinte significa entender a Literatura como discurso limite, situada na fronteira da rede de enunciação tópica da sociedade, enunciados que produzem as próprias condições de existência, dos assuntos e dos gêneros que submete à própria enunciação.

Ao mencionar a ideia de um "limite", deve-se entender que o discurso literário subjaz à fronteira da enunciação discursiva, que não é a de uma constituição tópica, em que enunciados estão validados por instituição e rotinas de comunicação, nem é a não tópica, de enunciados que circulam nas sombras, sendo rejeitados por instituição e produtores ${ }^{37}$. Trata-se, portanto, de uma zona paratópica, aquela que está no total pertencimento e não pertencimento ao campo discursivo.

Para Maingueneau (2006, p. 92)

[...] o pertencimento ao campo literário não é, portanto, ausência de todo lugar, mas como dissemos, uma negociação entre o lugar e o não-lugar, um pertencimento parasitário que se alimenta de sua inclusão impossível. Trata-se daquilo que antes denominamos "paratopia".

37 C.f Maingueneau, 2010, p. 22. 
O discurso literário ganha força em sua própria falha, ou seja, a ausência de um espaço genuinamente literário o faz subverter todos os espaços tópicos. Desse mesmo modo, o autor do discurso literário ocupa essa mesma falha e é, portanto, o deslocado, que participa da sociedade de maneira enviesada. Por mais que se queira observar essa reflexão como metafórica, trata-se, na verdade, da observação literal do espaço ocupado por autores e autoras de literatura que, para acentuar a paratopia, aproveitam-se das mazelas sociais para estarem em uma posição limite da sociedade e, dessa forma, fazer emergir o discurso literário.

Nas ocasiões em que estamos diante de discursos literários, cujos autores e autoras valeram-se das próprias condições problemáticas de pertencimento integral à sociedade, Maingueneau (2006, p. 110) chamou tal paratopia de paratopia de identidade:

A paratopia de identidade - familiar, sexual, ou social - apresenta todas as figuras da dissidência e da marginalidade, literais ou metafóricas: meu grupo não é meu grupo. A paratopia familiar dos desviantes da árvore genealógica: crianças abandonadas, encontradas ao acaso, escondidas, bastardos, órfãos... A paratopia sexual dos (sic) travestis, homossexuais, transexuais... A paratopia social dos boêmios e excluídos de alguma sociedade: cidade, clã, grupo, classe social, Igreja, religião, nação... A paratopia de identidade pode até se tornar máxima, por menos que incida sobre o próprio pertencimento pleno à humanidade, tanto do ponto de vista físico, (que inscreve na carne a exclusão pela raça, a doença, a deficiência ou a monstruosidade) como moral (a do criminoso) ou a psíquica (do louco). 
Temos um ponto de grande interesse para avaliar o discurso literário Um homem chamado cavalo é meu nome, uma vez-tratar-se da paratopia de identidade força motriz que conflui para constituição do discurso, que é nosso objeto. No entanto, a expressão "identidade", que compõe a noção apresentada por Maingueneau, parece-nos mais problemática do que adequada para a identificação dessa paratopia. Vejamos, na próxima seção, esse problema.

\section{Problemas da paratopia de identidade e a paratopia do estigma.}

Em 2018, defendemos a tese A paratopia do estigma: identidade e relato de si no discurso Recordações do escrivão Isaías Caminha, de Lima Barreto ${ }^{38}$. Na ocasião, pareceu-nos mais produtivo e prudente substituir o termo "identidade" por "estigma", nos termos preconizados por Goffman (2001), fato que, neste estudo, também mostra-se conveniente.

Maingueneau (2006), para propor a noção de paratopia de identidade reflete sobre a tensão entre o espaço e um sujeito que o ocupa pensa a identidade como aquilo que revela o "problema", o "defeito", o "Outro", pois a falha paratópica, engrenagem da qual depende o discurso constituinte literário, nasce da interferência da inadequação entre o Outro e o espaço.

Ao propor a paratopia de identidade, Maingueneau (2006) localiza grupos historicamente perseguidos, grupos de sujeitos de-

38 Chaves, Ramon Silva. A paratopia do estigma: identidade e relato de si no discurso Recordações do escrivão Isaías Caminha, de Lima Barreto. 2018. $214 \mathrm{f}$. Tese (Doutorado em Língua Portuguesa) - Programa de Estudos Pós-Graduados em Língua Portuguesa, Pontifícia Universidade Católica de São Paulo, São Paulo, 2018. 
preciados, aqueles que, por um gesto histórico, social ou moral, são interpretados como "inadequações", sujeitos que, só podem participar da sociedade de maneira enviesada. $\mathrm{O}$ autor defende que

Enquanto discurso constituinte a instituição literária não pode de fato pertencer plenamente ao espaço social, mantendo-se antes na fronteira entre a inscrição e seus funcionamentos tópicos e o abandono a forças que excedem por natureza toda economia humana. Isso obriga os processos criadores a alimentar-se de lugares, grupos, comportamentos que são tomados num pertencimento impossível (MAINGUENEAU, 2006, p. 92).

Ao defender como "hipótese", a noção de paratopia de identidade, o analista do discurso sinaliza que essa paratopia está marcada por grupos cujo pertencimento é visto como inadequado, o $\mathrm{Ou}$ tro propriamente dito. Contudo, essa posição teórica que identifica o Outro - inadequado e não identificado - do Eu - identificado e adequado - é o princípio de alteridade

[...] para que ocorra a tomada de consciência, é necessário que haja diferença, a diferença em relação a um outro. É somente ao perceber o outro como diferente, que pode nascer, no sujeito, sua consciência identitária. A percepção da diferença do outro constitui de início a prova de sua própria identidade, que passa então a "ser o que não é o outro". A partir daí, a consciência de si mesmo existe na proporção da consciência que se tem da existência do outro. Quanto mais forte é a consciência do outro, mais fortemente se constrói a sua própria 
consciência identitária. É o que se chama de princípio de alteridade (CHARAUDEAU, 2009, p. 309).

Poderíamos, assim, pensar que a paratopia de identidade poderia ser substituída, de maneira simplificada, pela noção de paratopia de "alteridade". No entanto, ainda assim estaríamos diante de um projeto de pesquisa desconfortável, pois a "alteridade" - gestão entre Eu e o Outro -, não é suficiente para desestabilizar um sujeito de um lugar de dizer.

Pressupor a paratopia é o mesmo que entender que o enunciado literário emerge da falha entre o total pertencimento ao universo tópico e, ao mesmo tempo, a total marginalidade a esse pertencimento. Assim, o enunciado literário lança mão da posição problemática de sujeitos em uma comunidade para dar ignição ao discurso literário. Desse modo, podemos pacificar que, sendo a alteridade o efeito da identidade, é naquela que se edifica a paratopia. No entanto, parece-nos ainda pouco preciso que a alteridade seja bastante para evidenciar a "inadequação" do sujeito ao lugar do dizer.

Ergue-se, assim, o nosso projeto de pesquisa: sendo a paratopia um "lugar do dizer baseado no impossível pertencimento", ela não pode estar erigida na identidade, identidade - identificada - ou no seu efeito, a alteridade, mas na tensão entre uma identidade ideal e Outra, que porta um "defeito", uma marca capaz de fazer questionar o direito à fala de um enunciador. Esse traço capaz de problematizar o pertencimento de um sujeito a um espaço é o estigma.

Segundo Goffman (2001, p. 117)

[...] o estigma envolve não tanto um conjunto de indivíduos concretos que podem ser divididos em duas pilhas, 
a de estigmatizados e a de normais, quanto um processo social de dois papéis no qual cada indivíduo participa de ambos, pelo menos em algumas conexões e em algumas fases da vida. O normal e o estigmatizado não são pessoas, e sim perspectivas que são geradas em situações sociais durante os contatos mistos, em virtude de normas não cumpridas que provavelmente atuam sobre o encontro.

Nessa perspectiva, a discussão que se dá de paratopia de identidade mostra-se inconsistente, uma vez que estamos discutindo características que colocam os sujeitos em um "lugar" de exclusão. Para enunciar de um plano "paratópico", o autor precisa se localizar em uma zona problemática da própria constituição de si. Sujeitos marginalizados não são, por si mesmos, "paratópicos", mas é a condição de estar à margem que pode embrear um plano de produção enunciativa a partir de um "insustentável", pois

[...] a paratopia só é motor de uma criação quando implica a figura singular do insustentável que torna essa criação necessária. A enunciação literária é menos a manifestação triunfante de um "eu" soberano do que a negociação desse insustentável. Presente neste mundo e dele ausente, condenado a perder para ganhar, vítima e carrasco, o escritor não tem outra saída senão seguir em frente. É para escrever que preserva sua paratopia, e é escrevendo que pode se redimir desse erro (MAINGUENEAU, 2006, p. 115). 
Sendo assim, entender essa paratopia como de identidade é, de certo modo, excluir o efeito problemático do espaço de onde esses criadores enunciam, porque nem toda identidade é especialmente problemática,

a sociedade estabelece os meios de categorizar as pessoas e o total de atributos considerados como comuns e naturais para os membros de cada uma dessas categorias: Os ambientes sociais estabelecem as categorias de pessoas que têm probabilidade de serem neles encontradas. As rotinas de relação social em ambientes estabelecidos nos permitem um relacionamento com "outras pessoas" previstas sem atenção ou reflexão particular (GOFFMAN, 2001, p. 05).

A identidade é uma condição humana que, só em alguns casos específicos - onde há estigmas -, pode ser aproveitada como embreante de enunciados literários, pois "a noção de paratopia só interessa para uma análise do discurso literário se for remetida a 'contexto', se for tomada a um só tempo como condição e produto do processo criador" (MAINGUENEAU, 2006, p. 120). Assim, é a identificação social da inadequação entre a identidade virtual e a identidade social que é capaz de gerar a tensão e o problema de onde se embreará a enunciação literária.

Goffman (2001, p. 06) postula que

enquanto o estranho está à nossa frente, podem surgir evidências de que ele tem um atributo que o torna diferente de outros que se encontram numa categoria em que pudesse ser - incluído, sendo, até, de uma espécie 
menos desejável - num caso extremo, uma pessoa completamente má, perigosa ou fraca. Assim, deixamos de considerá-lo criatura comum e total, reduzindo-o a uma pessoa estragada e diminuída. Tal característica é um estigma, especialmente quando o seu efeito de descrédito é muito grande - algumas vezes ele também é considerado um defeito, uma fraqueza, uma desvantagem - e constitui uma discrepância específica entre a identidade social virtual e a identidade social real.

Entre a identidade virtual, plenamente idealizada e adequada aos contextos de circulação da enunciação e a identidade real, aquela atingida pelos sujeitos, pode existir uma interferência capaz de desestabilizar o pleno pertencimento do enunciador ao lugar de enunciação. É essa falha a responsável por tornar o lugar do dizer paratópico, não a identidade e é, por isso, que aceitamos como mais conveniente entender Um homem chamado cavalo é meu nome como discurso constituinte literário, cuja paratopia é embreada pelo estigma do louco e interno no manicômio.

\section{A paratopia do estigma louco e interno em Um homem chamado cavalo é meu nome.}

Nesta seção, analisamos a paratopia do estigma no discurso Um homem Chamado Cavalo é meu nome, de Stela do Patrocínio. Para isso, discutiremos os 10 enunciados que compõem o discurso ora analisado, observando, especificamente, a tensão enunciativa entre um enunciador marcado pela inadequação a um espaço de onde enuncia. 
Ao propor hipótese da paratopia do estigma, não queremos apenas promover a substituição do vocábulo "identidade" por outro, mas tencionar a categoria proposta por Maingueneau (2006), sobretudo, ao que se refere à "falha" de onde emana o impossível lugar.

Para isso, importa-nos uma variedade de observações acerca dos enunciados que analisamos, a começar pelo título:

\section{Um homem chamado ca- valo é meu nome}

Cabe-nos, nesse ponto, observar três instâncias de enunciação paratópica. A primeira, chamada por Maingueneau (2006) de pessoa, é o sujeito de carne e ossos, de onde a vida é o sustentáculo da enunciação. Nesse caso, a pessoa é Stela, a mulher interna da Colônia Juliano Moreira, diagnosticada com esquizofrenia. É a pessoa do enunciado que, de certo modo, só pode ser lido partindo da sublimação artística, com base no estatuto de "hiperproteção" (MAINGUENEAU, 2006), que possa nos fazer atribuir sentido, mesmo diante da falta de lógica literal da enunciação: não é provável que exista um nome "Um homem chamado cavalo".

A segunda instância é a de escritor. Essa instância nos parece muito problemática, uma vez que ela é simulada no caso do discurso que analisamos. Stela é a pessoa que confere a enunciação um corpo, mas quem a escreve e conduz o quadro hermenêutico do discurso é Viviane Mosé, sujeito que, de certo modo, também é garantia da enunciação, pois contrapõe-se ao estigma "louco" e "interno" a marca de "filósofa", materializando uma posição "máximo/mínimo" literário. Enquanto o estigma garante que o enunciado seja possível como ele está dado, é o escritor que garante que há sentido e erudição no mesmo enunciado. 
Da confluência inteiriça das duas primeiras instâncias nasce a terceira, o inscritor, que é "com efeito, tanto o enunciador de um texto específico como, queira ou não, o ministro da instituição literária, que confere sentido aos contratos implicados pelas cenas genéricas que dela se faz o garante” (Maingueneau, 2006, p. 136).

O inscritor passa, neste estudo, a ser a instância observada na enunciação de Um homem chamado cavalo é meu nome, porque essa instância unifica as duas primeiras no que Maingueneau chamou de "nó borromeano" (2006). Esse nó conduz a embreagem marcada pelas posições máximo/mínimo da enunciação, partindo do espaço e da inadequação.

No enunciado I, vê-se o seguinte,

Eu estou num asilo de velhos

\author{
Num hospital de tudo que \\ é doença
}

Num hospício lugar de maluco louco doido

Instala-se, no enunciado I, a engrenagem paratópica: a marca enunciativa do eu engrena a participação em sua própria paratopia, o lugar de exclusão e de pertencimento a outro lugar. Um enunciado que mostra uma existência problemática. Não se pode negligenciar, a dimensão dos "versos" na elaboração do quadro hermenêutico, as marcas de oralidade em "num”, promovendo ainda mais o "corpo" da enunciadora e, no último verso a ausência das 
vírgulas. O "lugar de maluco louco doido" é o ambiente paratópico que jogará adiante a extensão de toda a enunciação literária, maximizando as posições máximo e mínimo num ambiente em que o estigma, tensão entre a identidade virtual é agredida pela marca da loucura e da internação psiquiátrica.

Do enunciado II, destacamos apenas alguns trechos, pois se trata de um enunciado que não está versificado. É um testemunho ${ }^{39}$ de único parágrafo. Desse testemunho destacamos os seguintes recortes:

\section{I}

Eu vim parar na Colônia porque eu estava andando na rua Voluntários da Pátria ao lado do Luís, com um óculos, vestido azul, sapato preto, com uma bolsa branca com um dinheirinho dentro, porque eu ia pegar um ônibus e ia saltar na Central do Brasil [...]

O inscritor enuncia sobre a "internação", partindo do "injustificado". Não existe, no enunciado motivo bastante para uma internação, exceto o próprio movimento que não discute a internação por uma perspectiva da revolta, mas da inevitabilidade. $\mathrm{O}$ uso do vocabulário e a repetição, especialmente da conjunção "porque", engrenam o enunciado literário ainda mais, uma vez que assumem uma forma de dizer que só poderia ser incorporada pelas instâncias enunciativas.

39 C.f CARREIRA, 2015. 
[...] vim pra cá, estou como indigente, sem ter família nenhuma, morando no hospital, estou aqui como indigente, sem ter ninguém por mim, sem ter família e morando no hospital.

O encerramento do enunciado II acentua o estigma e, por isso, assevera a paratopia. A deixes operada instaura o lugar, o "hospital", mas essa construção de "lugar" é, em si mesma, da inadequação, uma vez que hospitais não são moradias. Morar em um hospital é, por si, o enrijecimento do estigma da loucura - da cura impossível e da eterna tentativa de cura. Além disso, há o esvaziamento das relações; "sem ter família", "estou aqui como indigente", "sem ter ninguém por mim", "sem ter família". A ruptura com as relações de afeto e familiares são, consequentemente, marca de uma existência flutuante - existir socialmente sem o pertencimento de laços.

O recorte III traz pelo enunciado os reforços paratópicos que vimos até então: na tensão entre a identidade virtual e real, o uso da "língua" se mostra como estatuto da loucura

\section{III}

Ainda era Rio de Janeira, Botafogo

Eu me confundi comendo pão

Eu perdi o óculos

Ele ficou com o óculos 
passou a língua no óculos para tratar o óculos com a língua

Ela na vigilância do pão sem poder ter o pão

Essa troca de sabedoria de ideia de esperteza

Dia tarde noite janeiro fevereiro dezembro

Fico pastando no pasto à vontade

Um homem chamado cavalo é meu nome

O bom pastor dá a vida pelas ovelhas

O início do enunciado III, "Ainda era Rio de Janeiro, Botafogo" mostra a tensão em relação ao espaço geográfico. Nesse caso, o "ainda" não mostra um lugar, mas uma fronteira com o desconhecido. Há a tensão por meio da lógica instaurada pelo quadro hermenêutico do discurso constituinte literário como, por exemplo, em "passou a língua no óculos para tratar o óculos com a língua". O recorte III traz o verso que dá título ao capítulo, "Um homem chamado cavalo é meu nome", que tem o sentido garantido porque o espaço é o do "pasto" e do "Fico pastando à vontade". 
IV

Eu estava com saúde Adoeci

Eu não ia adoecer sozinha não

Mas eu estava com saúde

Estava com muita saúde

Me adoeceram

Me internaram no hospital

E me deixaram internada

E agora eu vivo no hospital como doente

O hospital parece uma casa

O hospital é um hospital

Nesse enunciado, a paratopia está marcada pela ideia de "doença". O estar ou não estar doente reflete o "não lugar" que é o hospital, "parece" uma casa, mas, ainda assim, é um "hospital”. A emergência de um enunciado numa zona de conflito, da inadequação com os espaços, com a impossibilidade de dizer de outro modo. 


\section{V \\ É dito: pelo chão você não pode ficar}

Porque lugar de cabeça é na cabeça

Lugar de corpo é no corpo

Pelas paredes você também não pode

Pelas camas também você não vai poder ficar

Pelo espaço vazio você também não vai poder ficar

Porque lugar de cabeça é na cabeça

Lugar de corpo é no corpo

Em V, a paratopia se desenvolve por mencionar o enunciador deslocado e em constante movimento de inadequação; afinal, não há lugares onde se possa ficar. Um eterno trânsito dentro da própria inadequação. Não há, sequer, um "espaço vazio" que possa ser ocupado. A ordem vem de um Outro, "Você não pode ficar", que instaura a inadequação do corpo do enunciador. 


\section{VI}

Eu vim do Pronto Socorro do Rio de Janeiro

Onde a alimentação era eletrochoque, injeção e remédio

E era um banho de chuveiro, uma bandeja de alimentação

E viagem sem eu saber para onde ia

Vim parar aqui nessa obra, nessa construção nova

Em VI, o estigma é a engrenagem entre o ponto de partida e o ponto de chegada do enunciador: "Eu vim" e "Vim parar aqui". O ponto de partida é um "Pronto Socorro", o de chegada é uma "construção nova", uma edificação onde a alimentação é mais do que a comida, mas o tratamento medicamentoso e violento dado aos sujeitos. Além disso, esse estigma é reforçado pelo não lugar "Eu vim sem saber para onde eu ia".

\section{VII}

O remédio que eu tomo me faz passar mal

E eu não gosto de tomar remédio pra ficar 


\section{passando mal}

Eu ando um pouquinho, cambaleio, fico

cambaleando

Quase levo um tombo

E se eu levo um tombo eu levanto

Ando mais um pouquinho, torno a cair

Em VII, o enunciador apresenta um paradoxo, pois "O remédio" o faz "passar mal". Essa disparidade é normalizada, porque não há uma reclamação efusiva como se poderia imaginar em uma situação extrema, mas um relato sobre não se sentir bem com a medicação. $\mathrm{O}$ que nos leva à reflexão sobre as condições de tratamento para os chamados distúrbios psíquicos, uma vez que essas condições não são doenças, o tratamento por meio de drogas e eletrochoque gera um efeito de estigma em identidades que não correspondem às ideais. Essa tensão pela busca do tratamento compõe a engrenagem paratópica.

\section{VIII}

Estar internada é ficar todo o dia presa

Eu não posso sair não deixam eu passar pelo portão

Maria do Socorro não 
deixa eu passar pelo portão

Seu Nelson também não deixa eu passar pelo portão

Eu estou aqui há quase vinte e cinco anos

Em VIII, a paratopia se marca pela segregação. Existe, em todo o discurso, uma alternância entre a paratopia engendrada pelo estigma da loucura e, de modo correlato, a de "interno" ou "preso". Esses dois estigmas são os responsáveis pelo desenrolar da enunciação do discurso constituinte literário analisado.

\section{IX}

Mais de quinhentos milhões e quinhentos mil moradores

Morando no Teixeira Brandão, Jacarepaguá

Núcleo Teixeira Brandão, Jacarepaguá

E todo dia dá segunda terça quarta quinta...

Em IX, o espaço onde a pessoa enuncia é identificado, mas essa identificação ratifica o não lugar, pois o núcleo Teixeira Brandão, da Colônia Juliano Moreira, é o "hospital" que é "um hospital". A ideia de moradia é, nesse sentido, incompatível. Além disso, o último verso aciona a ideia de "eterno", pois todos os dias são compostos pela semana inteira. 


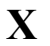

Sinto muita sede muito sono muita preguiça

Muito cansaço

Fico na malandragem na vagabundagem como marginal

E como malandra como marginal como malandra na malandragem

$\mathrm{Na}$ vagabundagem e na malandragem como marginal.

Em X, a paratopia chega ao seu ponto de maior tensão. $\mathrm{O}$ enunciador assume-se como marginal. A figura à margem é, estritamente, o ponto de maior tensão da paratopia, de onde o enunciador pode encenar o próprio pertencimento a uma sociedade que o rejeita. A ideia de "malandro", "marginal" mostra, efetivamente, a noção de estigma, daqueles que, por uma marca, não podem pertencer a um espaço nem pretender uma identidade, mas viver na condição de entremeio que essa marca impõe.

\section{Conclusão}

$\mathrm{Na}$ escrita desse capítulo apresentamos a hipótese de pesquisa "A paratopia do estigma", partindo da análise do discurso de Um 
homem chamado cavalo é meu nome, de Stela do Patrocínio e analisamos o processo de criação desse discurso literário. Neste estudo, nos orientamos pelo estigma da loucura para uma análise capaz de verificar o processo de criação literária de um discurso que está situado entre uma posição de total descrédito, do que não faz sentido, e de crédito total, do que tem sentido artístico.

Sob essas percepções, observamos os esforços de nosso teórico de base que incidem sobre a Literatura. Nessa senda, Maingueneau (2006) rompe com a tradição de análises literárias mais difundidas e apreende o discurso literário como constituinte; enunciados auto e heteroconstituintes capaz de ser o archeion de uma coletividade. Essa reflexão tem como consequência a observação da paratopia, que é a engrenagem do discurso constituinte literário: uma vez que esses discursos "são tomados por um pertencimento impossível" (MAINGUENEAU, 2006, p. 92), resta a esses enunciados partirem do "não lugar", uma fenda gerada entre os espaços tópicos do dizer da coletividade que o abarca.

Dessas proposições nasce a noção "paratopia de identidade", conceito apregoado por Maingueneau (2006) para definir enunciados literários, cuja engrenagem paratópica funda-se em enunciadores/autores que aproveitam o lugar do dizer problemático para construir o ponto de ignição paratópica de seus enunciados literários.

Essa reflexão, para essa análise do discurso, pareceu-nos mais problemática do que assertiva, na medida em que concordamos que a paratopia funda-se no "não lugar". Ao concordarmos com isso, não nos pareceu adequado dizer que há identidade inadequada, pois a identidade é a identificação de um sujeito com um grupo e com um espaço. No entanto, admitimos que há sujeitos que por estarem relacionados a um grupo ou a uma marca física ou 
psicológica podem ter o seu pertencimento a algum lugar problematizado. Desse modo, associamo-nos ao postulado por Goffman (2001) em sua noção de estigma, que é uma marca que desestabiliza a identidade de lugares de enunciação. Para Goffman, os lugares pressupõem os sujeitos que têm permissão de os ocuparem, mas, se esses sujeitos recebem uma marca negativa, esse pertencimento passa a ser problematizado e até retirado desses sujeitos. Tal marca é o estigma.

Desse modo, arriscamo-nos a propor nossa própria hipótese de pesquisa: a paratopia do estigma para avaliar o discurso Um homem chamado cavalo é meu nome, de Stela do Patrocínio. Tal hipótese de avaliação, foi confirmada a partir da avaliação do corpus.

Para nossa análise, fizemos o levantamento das condições sócio-histórico e culturais de produção do discurso e observamos uma produção compartilhada entre Stela, a pessoa que sustenta o discurso com um corpo físico, marcada pela loucura e pela internação e Viviane Mosé, a garante filósofa que opera na construção de um quadro hermenêutico literário, compondo a cenografia e unindo-se à Stela numa posição "mínimo/máximo" capaz de garantir o discurso literário em sua união como "inscritoras".

De nossa análise, percebemos que o enunciador se ocupa de marcar o enunciado por meio do estigma da loucura e da internação psiquiátrica, operando pelo "não lugar”. A posição mínima é marcada pela ilogicidade dos enunciados, a falta de pontuação e pela temática das rotinas psiquiátricas. A posição máxima é marcada pela cenografia de poesia e pelas condições de produção do universo artístico de onde parte o enunciado.

Assim, temos um estudo preliminar dessa hipótese de pesquisa que se abre humildemente para crítica de nossos pares. Espera- 
mos que nossa proposição não se pareça fechada, mas interessada em produzir discussão dentro do escopo teórico metodológico da Análise do Discurso, produzida no Brasil, especialmente, sobre a categoria paratopia de Maingueneau.

\section{Referências}

BAKHTIN, Mikhail. Estética da Criação Verbal. - Trad. Paulo Bezerra. São Paulo: Martins Fontes, 2003.

BOURDIEU, Pierre. As regras da Arte. - Trad. Maria Lúcia Machado. São Paulo: Companhia das Letras, 1998.

CARREIRA, Rosângela Aparecida Ribeiro. A paratopia testemunho documental e o discurso da negritude em Vencidos e Degenerados. 2015. 250 f. Tese (Doutorado em Língua Portuguesa) - Pontifícia Universidade Católica de São Paulo, São Paulo, 2015.

CHARAUDEAU, Patrick. Identidade social e identidade discursiva, o fundamento da competência comunicacional, In: PIETROLUONGO, Márcia. (org.) O trabalho da tradução. Rio de Janeiro: Contra Capa, 2009, p. 309-326, 2009.

CHAVES, Ramon Silva. A paratopia do estigma: identidade e relato de si no discurso Recordações do escrivão Isaías Caminha, de Lima Barreto. 2018. 214 f. Tese (Doutorado em Língua Portuguesa) - Programa de Estudos Pós-Graduados em Língua Portuguesa, Pontifícia Universidade Católica de São Paulo, São Paulo, 2018.

EAGLEATON, Terry. How to read a poem. EUA - Blackwell publishing, 2007.

FOUCAULT, Michel. A história da loucura na Idade Clássica.

- Trad. José Teixeira Coelho Netto; Revisão de texto: Antonio de Pádua Danesi; Revisão de provas: Aníbal Mari, José Bonifácio Caldas, Plínio Martins Filho e Vera Lúcia 
B. Bolognani; Produção: Plinio Martins Filho. São Paulo: Perspectiva, 1972.

GOFFMAN, Erving. Estigma: notas sobre a manipulação da identidade deteriorada. Trad. Mathias Lamberth. $4^{\mathrm{a}}-$ ed. São Paulo - LTC, 2001.

LAJOLO, Marisa. O que é Literatura? - 5ª ed. São Paulo - Editora Brasiliense, 1984.

MAINGUENEAU, Dominique. A Análise do Discurso e suas fronteiras. Matraga. Rio de Janeiro, v.14, n.20, 2007, pp. 13-37.

MAINGUENEAU, Dominique. Discurso literário. - Trad. Sírio Possenti. São Paulo - Contexto, 2006.

MAINGUENEAU, Dominique. O Discurso Pornográfico. Trad. Marcos Marcionilo, São Paulo: Parábola, 2010.

MOSÉ, Viviane. Stela do Patrocínio - Uma trajetória poética em uma instituição psiquiátrica. In: PATROCÍNIO, S. Reino dos bichos e dos animais é o meu nome. Rio de Janeiro: Azougue, 2001. p. 19-31.

PATROCÍNIO, Stella. Reino dos bichos e dos animais é o meu nome. Organização Viviane Mosé. Rio de Janeiro - Azougue, 2001.

ZARA, Telma Beiser de Melo. "Me transformei com esse 'falatório' todinho": cotidiano institucional e processo de subjetivação em Stela do Patrocínio. Dissertação (Mestrado em Ciências Sociais) - Universidade Estadual do Oeste do Paraná. Campus de Toledo. Centro de Ciências Sociais e Humanas. 2014. 